(C) 2020 John Wiley \& Sons Ltd. This article may be used for non-commercial purposes in accordance with Wiley Terms and Conditions for Use of Self-Archived Versions

\title{
Effects of Enteromyxum spp. (Myxozoa) infection in the regulation of intestinal E-cadherin: turbot against gilthead sea bream
}

\section{Short title: Intestinal E-cadherin regulation in enteromyxoses}

Paolo Ronza $a^{\mathrm{a}^{*}}$; Itziar Estensoro ${ }^{\mathrm{b}}$; Roberto Bermúdez ${ }^{\mathrm{a}, \mathrm{c}}$; Ana Paula Losada ${ }^{\mathrm{a}}$; Gregorio Pérez-Cordón ${ }^{\mathrm{b}, \mathrm{d}}$; Belén G. Pardo ${ }^{\mathrm{c}, \mathrm{e}}$; Ariadna Sitjà-Bobadilla ${ }^{\mathrm{b}}$; Mª Isabel Quiroga ${ }^{\mathrm{a}, \mathrm{c}}$

aDepartamento de Anatomía, Producción Animal y Ciencias Clínicas Veterinarias, Universidade de Santiago de Compostela, Lugo, Spain.

bFish Pathology Group, Instituto de Acuicultura Torre de la Sal, Castellón, Spain.

'Instituto de Acuicultura, Universidade de Santiago de Compostela, Santiago de Compostela, Spain

${ }^{\mathrm{d} C}$ Cryptosporidium Reference Unit, Public Health Wales, Singleton Hospital, Swansea, UK.

eDepartamento de Zoología, Genética y Antropología Física, Universidade de Santiago de Compostela, Lugo, Spain.

*Corresponding author:

Dr. Paolo Ronza

Departamento de Anatomía, Producción Animal y Ciencias Clínicas Veterinarias

Universidade de Santiago de Compostela - Campus Terra

27002 Lugo

Phone: (+34) 982822306

E-mail: paolo.ronza@usc.es

\section{Acknowledgments}


The authors are in debt with Professor Jaume Pérez Sánchez for providing access to the

24 gilthead sea bream transcriptomic database (http://www.nutrigroupiats.org/seabreamdb). The authors thank S. Maceiras, J. Monfort and L. Rodríguez for histological processing, R. del Pozo and L. Insua for technical assistance with the qPCR assays, fish husbandry and samplings and M.C. Piazzon for critical reading of the manuscript. This work has been funded by the Spanish Ministry of Economy and Competitiveness and the European Regional Development Fund (ERDF) through the projects AGL2015-67039-C3-1-R, AGL2015-67039-C3-3-R and AGL-2013-48560-R, and by the Horizon 2020 Framework Programme through ParaFishControl Project (634429). I.E. was contracted under APOSTD/2016/037 grant by the "Generalitat Valenciana” and G.P.-C. under the “Juan de la Cierva” program, granted by the Spanish Ministry of Science and Innovation (JCI-2011-09438).

\section{Data Availability Statement}

The authors confirm that the data supporting the findings of this study are available within the article and its supplementary materials.

\section{Abstract}

Enteromyxoses are relevant diseases for turbot and gilthead sea bream aquaculture. The myxozoan parasites invade the intestinal mucosa, causing a cachectic syndrome associated to intestinal barrier alteration, nonetheless, their pathological impact is

42 different. Turbot infected by Enteromyxum scophthalmi develop more severe intestinal 43 lesions, reaching mortality rates of $100 \%$, whereas in E. leei-infected gilthead sea bream, the disease progresses slowly, and mortality rates are lower. The mechanisms underlying the different pathogenesis are still unclear. We studied the distribution and expression 
47 intestine of both species by immunohistochemistry and quantitative PCR, using the same immunohistochemical protocol and common primers. The regular immunostaining pattern observed in control fish turned into markedly irregular in parasitized turbot, showing an intense immunoreaction at the host-parasite interface. Nevertheless, Ecadherin gene expression was not significantly modulated in this species. On the contrary, no evident changes in the protein distribution were noticed in gilthead sea bream, whereas a significant gene down-regulation occurred in advanced infection. The results contribute to the understanding of the different host-parasite interactions in enteromyxoses. Host and parasite cells appear to establish diverse relationships in these species, which could underlie the different pathological picture.

57 Keywords: Enteromyxosis, Myxosporea, cell junctions, intestinal barrier, host-parasite 58 interaction

\section{Introduction}

60 Enteromyxoses caused by the intestinal myxozoan parasites Enteromyxum scophthalmi and E. leei pose a serious threat for marine aquaculture. These infections show fast spreading in productive units, given the direct fish-to-fish transmission of Enteromyxum spp., and provoke relevant economic losses for mortality and worsening of productive performances (Sitjà-Bobadilla \& Palenzuela, 2012). The parasitic stages invade the digestive tract and then grow and proliferate in the lining epithelium, causing gut

66 inflammation and impaired absorptive function (Bermúdez et al., 2010; Estensoro et al., 67 2011; Fleurance et al., 2008; Ronza, Robledo, et al., 2019). (Solea senegalensis) grown in a turbot farm suffering an outbreak were also found to be infected by this myxozoan, although with no obvious disease signs until they were 
examined (Palenzuela, Redondo, López, \& Álvarez-Pellitero, 2007). Turbot is highly susceptible to enteromyxosis, showing serious lesions and high morbidity and mortality rates, to the extent that the disease can affect up to $100 \%$ of fish in a farming unit. The infection starts in pyloric caeca or anterior intestine and subsequently spreads along the entire gut (Redondo, Palenzuela, \& Álvarez-Pellitero, 2004). Infected fish develop catarrhal enteritis of increasing severity throughout the disease (Bermúdez et al., 2010).

On the other hand, E. leei affects a wide range of fish species, with different host susceptibility (Sitjà-Bobadilla \& Palenzuela, 2012). Sharpsnout sea bream (Diplodus puntazzo) and tiger puffer (Takifugu rubripes) are among the most susceptible species, for which the disease constitutes a limiting factor and threatens the viability of their aquaculture (Rigos \& Katharios, 2010). By contrast, enteromyxosis usually causes a subchronic disease in gilthead sea bream (GSB, Sparus aurata) with accumulated mortality below 20\% (Sitjà-Bobadilla \& Palenzuela, 2012). Unlike turbot, the intestinal epithelial integrity is always preserved in GSB, even in the most heavily infected cases (Fleurance et al., 2008). Field and experimental data indicate that the distal part of the intestine is the first and main target site of the parasite in this species (Estensoro, Redondo, Alvarez-Pellitero, \& Sitjà-Bobadilla, 2010). In both species, turbot and GSB, the parasitization is associated to a cachectic syndrome characterized by weight loss, anorexia and amyotrophy, and no effective therapeutic options are currently available (Sitjà-Bobadilla \& Palenzuela, 2012). The pathogenesis of the diseases involves the loss of the intestinal barrier function, although the mechanisms underlying the differences in the magnitude of the lesions are still unclear (Ronza, Robledo, et al., 2019; Sitjà-Bobadilla \& Palenzuela, 2012).

E-cadherin is the main protein of the adherens junctions, one of the most important components for epithelial cell-cell junctional integrity. In mammals, its alteration has 
been reported in a variety of conditions associated to gastrointestinal disorders and has been related to apoptosis, cell shedding and disturbances in secretory cells differentiation (Schneider et al., 2010). In fish, E-cadherin gene expression was modulated in the intestine of Atlantic salmon in response to an experimental dietary treatment affecting intestinal fluid permeability (Hu et al., 2016). It is an evolutionary conserved protein. In particular, the C-terminal region of the protein, corresponding to the cytoplasmic domain, remained quite conserved from Placozoa to human (Hulpiau \& van Roy, 2011). Recently, an immunohistochemical technique for the detection of E-cadherin was set up in turbot using an anti-human E-cadherin commercial antibody (Ronza, Villamarín, et al., 2019).

In this work, we aimed to advance our knowledge of the pathogenesis of the intestinal barrier dysfunction associated to enteromyxoses, by investigating the changes in the protein distribution and gene expression of E-cadherin in the digestive tract of $E$. scophthalmi-infected turbot and E. leei-infected GSB. In both species, the immunohistochemical protocol described by Ronza et al. (2019) together with quantitative PCR analysis using common primers was employed.

\section{Materials and Methods}

\section{Experimental design and histopathology}

The experimental infection of turbot with E. scophthalmi by oral intubation and of GSB with E. leei by effluent exposure were previously described (see Estensoro, CalduchGiner, Kaushik, Pérez-Sánchez, \& Sitjà-Bobadilla, 2012; Robledo, Ronza, et al., 2014). Briefly, for turbot, a group of naïve fish received an oral inoculum of infected turbot intestinal scrapings, whereas another group (CTRL) was intubated with PBS. For GSB, a group naïve fish received water effluent from a donor tank holding E. leei-infected GSB, whereas another was kept unexposed (CTRL). 
In both trials, tissue samples were collected at different time points in Bouin’s fluid and in RNAlater for histopathological and molecular techniques, respectively. The status of CTRL and experimentally infected fish was assessed by light microscopy on H\&E, toluidine blue and Giemsa stained sections. Challenged turbot were classified into three groups (slightly, moderately and severely infected) according to the histopathological grading described by Bermúdez et al. (2010). The pyloric caeca and posterior intestine from 8 CTRL and 8 infected turbot at 24 and 42 days post-inoculation (DPI) were used. In order to increase the uniformity of the samples, infected turbot at 24 DPI were chosen among those graded as moderately infected and turbot at 42 DPI among those graded as severely infected. Challenged GSB were classified into two groups: moderately and severely infected according to a semiquantitative scale described in Picard-Sánchez et al. (2019). Samples used in the study include anterior and posterior intestine of 6 CTRL and 10 infected fish at 51, 91 and 133 days post-exposure (DPE). For gene expression, only posterior intestine was used, to have a representative number of fish in each grade.

Both infection trials were carried out at the facilities of the Institute of Aquaculture Torre de la Sal (IATS) in accordance with national (Royal Decree RD1201/2005, for the protection of animals used in scientific experiments) and institutional regulations (CSIC, IATS Review Board) and the current European Union legislation on handling experimental animals.

\section{Sequence comparison and primer design}

140 Available E-cadherin nucleotide and aminoacidic sequences from for turbot, human and 141 GSB (GenBank accession numbers MG137250, AB025106.1 and KF861995.1, 142 respectively) were compared using Clustal X 2.0 software, and BLASTN 2.9.0 and BLASTP 2.6.1 online programs (Altschul et al., 1997, 2005; Larkin et al., 2007). Given the protein and gene similarity of E-cadherin between turbot and GSB, common primers 
were designed, based on the mRNA sequences. After analysis, common sequence regions between turbot and GSB were identified and primers were designed using Primer Express

Paraffin sections ( $3 \mu \mathrm{m}$ thick) from Bouin’s fixed tissue samples were dewaxed in xylene and rehydrated through a graded ethanol series. The assays were carried out with a previously developed protocol (Ronza, Villamarín, et al., 2019), using an automated stainer (Dako Autostainer, Dako, Glostrup, Denmark) after the antigen retrieval step, in order to standardize the immunostaining. Briefly, the primary antibody (1:50 working dilution, mouse monoclonal antibody to human E-cadherin, clone NCH-38, M3612, Dako) was incubated during $2 \mathrm{~h}$ at room temperature. After 30 min incubation with HRPlabelled secondary antibody, the peroxidase reaction was developed with a diaminobenzidine-positive chromogen (EnVision+ System-HRP kit, K 4011; Dako), achieving the desired signal after 1 min of incubation. The sections were washed three times for $5 \mathrm{~min}$ in $0.1 \mathrm{M}$ phosphate buffered saline containing $0.05 \%$ Tween-20 between all subsequent steps. After counterstaining with haematoxylin, sections were unloaded by the Autostainer, dehydrated and coverslipped with DePeX mounting medium (Gurr ${ }^{\circledR}$, BDH Prolabo, VWR International, Ltd. UK). In order to test the specificity of the immunoreaction, positive (human tissue) and negative (replacement of the primary antibody by PBS) controls were included.

\section{Gene expression analysis}

167 Tissue samples preserved in RNAlater were kept at $4^{\circ} \mathrm{C}$ during $24 \mathrm{~h}$ and stored at $-20^{\circ} \mathrm{C}$ until RNA extraction. Total RNA was extracted from tissues of CTRL and challenged fish using TRIZOL Reagent (Life Technologies, Carlsbad, CA, USA) according to the 
manufacturer's recommendations. RNA quality and quantity were evaluated using a

171 Bioanalyzer (Agilent Technologies) and a NanoDrop ${ }^{\circledR}$ ND-1000 spectrophotometer

172 (NanoDrop ${ }^{\circledR}$ Technologies Inc), respectively. Good quality RNA (RIN > 7.5) was reverse transcribed $(1 \mu \mathrm{g})$ into cDNA with random primers using AffinityScript Multiple

174 Temperature cDNA Synthesis kit (Agilent Technologies) following the supplier's 175 protocol. The qPCR analysis was carried out in a MX3005P thermocycler (Stratagene) using $2 \mu \mathrm{l}$ of cDNA per reaction and $300 \mathrm{nM}$ of each primer in a final volume of $20 \mu \mathrm{l}$ according to the Brilliant III Ultra-Fast SYBR ${ }^{\circledR}$ Green QPCR Master Mix (Agilent Technologies) manufacturer's instructions. The constitutively expressed ribosomal protein S4 (RPS4), proved to be stably expressed in turbot (Robledo, Hernández-Urcera, et al., 2014), was chosen as the house-keeping gene for sample normalisation. Each sample was performed in triplicate for accuracy and error estimation including one reverse-transcription-negative control for each gene. Fluorescence readings at the end of each cycle were used to estimate threshold cycle values (Ct). Values were normalized to RPS4 and fold change at transcript level was determined with the relative quantitative method $(\Delta \Delta \mathrm{Ct})$ (Livak \& Schmittgen, 2001) using data from CTRL fish as reference values. Prior to quantitative analysis, a standard curve was constructed using six serial dilutions of cDNA (from 1,000 to $0.01 \mathrm{ng}$ ) and the efficiency of each primer set was determined. Each sample was analysed for primer-dimer, contamination, or mispriming by inspection of their dissociation curves.

\section{Statistical analysis}

191 The statistical analysis of gene expression in turbot was performed with SPSS Statistics 20.0 software (SPSS Inc., Chicago, Illinois, USA). Data were expressed as mean \pm SEM, and significance of differences was determined by Student's $t$-test, after checking that 
data follow a normal distribution using Shapiro-Wilk test. Results were considered significant at $P<0.05$.

In GSB, data on gene expression was analysed using SPSS 21.0. by one-way analysis of variance (ANOVA) analysis followed by a Student-Newman-Keuls (SNK) post hoc test. A $P$ value $<0.05$ was considered statistically significant.

\section{Results}

\section{Histopathology}

201

The most evident differences were noticed at an advanced stage of infection, when both species showed a massive parasitic load in the lining epithelium of the entire intestinal tract (Figure 1A-D). Inflammatory infiltration was observed in the lamina propriasubmucosa in both cases, although more severe in turbot. On the other hand, the epithelial alterations were quite different: turbot intestine showed large areas of epithelial sloughing and the characteristic "scalloped shape" of the remaining lining epithelium. As well, enterocyte alterations consistent with necrotic and apoptotic changes were often observed (Figure 1A, C).

\section{Sequence comparison and primer design}

210 The alignment performed between turbot and GSB E-cadherin resulted in $80 \%$ and $77 \%$

211 identity scores of the nucleotide (Supporting file 1) and aminoacidic sequences, respectively. In addition, the E-cadherin sequences of the two species showed similar

213 results when compared to human: the identity scores of the nucleotide and aminoacidic sequences were $71 \%$ and $53 \%$, respectively, in the turbot-human comparison, and $74 \%$ 215 and 50\% in the case of GSB-human.

216 A set of common primers targeting the conserved regions of E-cadherin was designed 
CAGCTGCCTTCAGGTTGTCAT) to amplify a fragment of 105 bp in length of the Ecadherin gene in both species (Supporting file 1).

Homogeneous immunostaining of the lining epithelium located at the cell-cell junction area with a basolateral position was observed in CTRL (healthy) fish of both species (Figure 2A, B). The distribution pattern of E-cadherin in the intestinal mucosa did not substantially change in fish with moderate infection, but a more intense staining was noticed surrounding the parasitic structures in turbot (Figure 2C, D). The severely parasitized specimens of this species showed a clear alteration of the immunostaining, consisting in a disordered and irregular distribution pattern of E-cadherin in the epithelium, with areas of scant immunoreaction interspersed with other of intense staining, particularly at enterocyte-parasite interface (Figure 2E). On the contrary, the distribution pattern did not seem to be particularly affected by the massive presence of parasites in GSB (Figure 2F). Within each species, the immunohistochemical results were analogous between the anterior and posterior part of the intestine (Figure 3A-D).

\section{Gene expression analysis}

qPCR assays were developed to analyze the gene expression of E-cadherin in the digestive tract of parasitized turbot and GSB and their respective CTRL. Results showed one clear single peak in each case using the common primers designed, indicating the suitability of the developed method. The transcriptional levels indicated a significant $(P$ $<0.05$ ) down-regulation of E-cadherin in the posterior intestine of severely infected GSB, with a decreasing trend with disease worsening (Figure 4). On the contrary, no significant differences were found between CTRL and infected turbot, neither in anterior nor in the posterior region of the intestine, although both regions showed a trend to up-regulation during moderate infection (Figure 5A, B). 
244 In this work, the immunohistochemical distribution and gene expression of E-cadherin in

245 the intestine of fish parasitized by Enteromyxum spp. were analysed. These myxozoan

246 parasites colonize the lining epithelium causing a cachectic syndrome characterized by

247 anorexia and weight loss. Nevertheless, the parasitosis shows a different course 248 depending on the species affected; in particular, turbot shows high mortality rates 249 associated to severe catarrhal enteritis while in GSB the intestinal lesions are milder and 250 mortality rates lower. Understanding the pathophysiology of gut barrier in the pathogenesis of these diseases appears to be key to unravel the mechanisms underlying the different susceptibility.

The immunohistochemical results indicate a change in the distribution pattern of Ecadherin in turbot, with loss of homogeneity and enhanced presence at the enterocyteparasite interface. In other parasitosis leading to intestinal barrier dysfunction, the pathogenesis involves the disassembly of cell-cell junctions and cytoskeleton, including the relocation of junctional proteins (Di Genova \& Tonelli, 2016). As well, oxidative stress was demonstrated to induce redistribution of E-cadherin and other junctional proteins, causing an increment in intestinal permeability in mice (Rao, Basuroy, Rao, Karnaky, \& Gupta, 2002). In turbot enteromyxosis, evidences of enhanced nitric oxide production and occurrence of oxidative stress have been highlighted (Losada, Bermúdez, Faílde, \& Quiroga, 2012; Robledo, Ronza, et al., 2014). The relocation of E-cadherin may 263 play a role in the pathogenesis of the characteristic severe epithelial desquamation observed in this species. It was demonstrated that the loss of E-cadherin from cell-cell junctions is related to anoikis (Fouquet et al., 2004), a form of apoptosis induced by loss of anchorage to the extracellular matrix. The occurrence of anoikis in turbot enteromyxosis was previously hypothesized because of the increasing number of 
apoptotic enterocytes observed during the infection by histology (Bermúdez et al., 2010) and immunochemistry to active caspase-3 (Losada, Bermúdez, Faílde, de Ocenda, \& Quiroga, 2014). Moreover, RNA-seq analysis of the intestine of E. scophthalmi-infected turbot also highlighted the up-regulation of different pro-apoptotic genes (Robledo, Ronza, et al., 2014).

On the contrary, the presence of E. leei, even in the case of severe parasitization, affected to a lesser extent the distribution of E-cadherin in GSB. The labelling pattern did not appear particularly altered compared to CTRL fish and there was no E-cadherin accumulation surrounding the parasite plasmodia. This suggests a different interaction between fish and myxozoan cells in this host-parasite scenario.

Once penetrating the host lining epithelium, both Enteromyxum species dwell, grow and proliferate in the paracellular space between enterocytes (Cuadrado et al., 2008; Redondo, Quiroga, Palenzuela, Nieto, \& Álvarez-Pellitero, 2003). The intricacies of the relationship between host and myxozoan cells and their interaction during the infection are still far to be fully understood. In GSB and turbot enteromyxoses, Redondo \& Álvarez-Pellitero (2009, 2010b) demonstrated the involvement of lectin/carbohydrate interactions between host and parasite cells in the mechanisms of adhesion and invasion. These authors suggested that the differences observed between the two fish species could aid to explain the differences in the severity of the related diseases (Redondo \& Álvarez-Pellitero, 2010a). Nevertheless, the existence, nature and role of cell-cell junctions between these myxozoans and their hosts is an aspect to be elucidated. Myxozoa, as members of the Cnidarian phylum, might theoretically present all ancestral eumetazoan types of cell junctions. However, it is difficult to identify them because they are often atypical or inconspicuous (Gruhl \& Okamura, 2015). In addition, it is still unclear how junctions can be formed between cells of different species, given the complexity and specificity of the 
formation of cell junctions in an organism (Cavey \& Lecuit, 2009; Shao et al., 2017).

Furthermore, in an infection scenario, the parasite might exploit the host cells' capabilities

to form junctions to subvert the defence response or simply to gain purchase of the host, as well as the host may alter the structure of its cell junctions to prevent formation of junctions with parasite cells (Gruhl \& Okamura, 2015). Structures resembling gap junctions have been described between plasmodia of E. scophthalmi and host intestinal epithelium (Redondo et al., 2003), while close interdigitating membranes of primary cells of E. leei with host cells have been observed at TEM (authors' unpublished data). The genomic and transcriptomic characterization of Enteromyxum spp. would greatly help to elucidate this aspect, and recently there have been promising progresses on this front (Chang et al., 2015; A. Picard-Sánchez et al., 2017; Shpirer et al., 2014).

The scant or even absent development of mature spores of E. scophthalmi observed in turbot, both in spontaneous and experimental infections, together with the particular E-cadherin might also represent a strategy to gain purchase of the host and ensure its survival once the epithelium starts to desquamate. In this sense, the presence of parasitic stages covered by mucosal remnants/detached cells in the intestinal lumen was often 313 reported, and it has been interpreted as a strategy to get protection from external 314 conditions until the invasion of a new host (Bermúdez et al., 2010; Losada et al., 2014; Redondo et al., 2003).

The two host-parasite scenarios analysed also showed different results concerning the Ecadherin gene expression. In the present work, a qPCR method has been developed for 
318 the amplification of a fragment of E-cadherin gene using common primers for both species. The optimized assay showed good specificity and sensitivity for both fish species. Intestinal E-cadherin down-regulation is usually observed in mammal's diseases characterized by high levels of pro-inflammatory molecules, such is the case of inflammatory bowel disease, where it has been related with the weakening of cell-cell adhesion in the lining epithelium (Arijs et al., 2011; Sanders, 2005). At this purpose, the down-regulation of E-cadherin gene expression found in severely-parasitized GSB, where a strong local immune response has been described (Pérez-Cordón et al., 2014), was the expected result and might underlie the development of intestinal barrier dysfunction in advanced infection. In addition, important changes in goblet cell composition and distribution, intestinal mucin expression and mucus glycoprotein profile have been described in E. leei-infected GSB (Estensoro et al., 2013; Estensoro, Redondo, et al., 2012; Pérez-Sánchez et al., 2013), and maturation and positioning of goblet cells was demonstrated to be impaired in mice with the E-cadherin gene inactivated (Schneider et al., 2010). In previous studies in this species, the intestinal gene expression of E-cadherin was also found to be modulated by some dietary interventions. In particular, it was significantly up-regulated in GSB fed a diet low in fish meal and fish oil, and it was restored when sodium butyrate was added (Estensoro et al., 2016). However, no changes were detected when fed with Next Enhance®150 (Pérez-Sánchez et al., 2015) or with olive oil bioactive compounds (Gisbert et al., 2017), and a lower expression was found in 338 the anterior intestine of fish fed DICOSAN or probiotics (Simó-Mirabet et al., 2017).

339 Why the down-regulation of E-cadherin gene expression detected in this study was not accompanied by an observable change in immunostaining in GSB needs to be further analyzed. The analysis of a greater number of time points might help to detect a possible later immunostaining alteration. However, changes in gene expression levels are 

Marcotte, 2012), as well as it is possible that a hypothetical small reduction in E-cadherin synthesis may not be detected by immunohistochemistry. Nevertheless, the distinctive immunolabelling in the parasitized fish of the two species and the different modulation 347 of the gene expression are worthy of further investigation.

Remarkably, despite the large body of evidence reporting an exacerbated intestinal immune response in turbot enteromyxosis (Ronza, Robledo, et al., 2019), we did not find a significant modulation of E-cadherin gene expression. A trend of up-regulation was noticed in moderate infection, a stage that, in this species, is characterized by cellular infiltrates in the lining epithelium, consistent with intraepithelial lymphocytes (Bermúdez et al., 2010). An intriguing hypothesis to be further investigated is the possible role of these cells in attempting to preserve the integrity of the intestinal mucosa. Intestinal intraepithelial lymphocytes express junctional molecules, including E-cadherin, and are thought to play a main role in sustaining the epithelial barrier function in mice parasitized by Eimeria vermiformis (Inagaki-Ohara et al., 2006).

Concluding, this work showed interesting changes of intestinal E-cadherin in both hostparasite scenarios, combining the use of morphopathological and molecular techniques. This is highly recommended in pathogenesis studies to get more exhaustive information, which can also be useful to glimpse the future direction of a research line. The loss of the physiological distribution of E-cadherin and its relocation at the enterocyte-parasite interface in parasitized turbot, whereas no evident changes were noticed in GSB, constitutes a remarkable finding that indicates diverse relationships with the parasite cells according to the host. This might contribute to explain the different host-parasite interactions and disease pathogenicity and deserves further attention. As well, more 
during the diseases. Along with E-cadherin as the main component of the adherens junctions, other proteins constituting the desmosomes and tight junctions (e.g. desmoglein 2, claudins, occludin, zonula occludens) have a relevant role in maintaining the gut barrier integrity, and several works in mammals reported their susceptibility to intestinal inflammation and/or as a target for intestinal parasites (Chelakkot, Ghim, \& Ryu, 2018; Di Genova \& Tonelli, 2016; Kamekura et al., 2015). To deepen our knowledge of the pathogenesis of barrier dysfunction during enteromyxoses, the exploration of possible perturbances in other junctional complexes should be included, ideally, combining the histopathological observations with transcriptomic and proteomic approaches. Understanding the relative weight of each factor (parasite, host immune response, oxidative stress) in the pathogenesis is crucial towards the design of control and therapeutic measures adapted to the singular fish-parasite model.

\section{References}

Altschul, S. F., Madden, T. L., Schaffer, A. A., Zhang, J., Zhang, Z., Miller, W., \& Lipman, D. J. (1997). Gapped BLAST and PSI-BLAST: a new generation of protein database search programs. Nucleic Acids Research, 25, 3389-3402. https://doi.org/10.1093/nar/25.17.3389

Altschul, S. F., Wootton, J. C., Gertz, E. M., Agarwala, R., Morgulis, A., Schaffer, A. A., \& Yu, Y. K. (2005). Protein database searches using compositionally adjusted substitution matrices. FEBS J, 272, 5101-5109. https://doi.org/10.1111/j.1742-4658.2005.04945.x

Arijs, I., De Hertogh, G., Machiels, K., Van Steen, K., Lemaire, K., Schraenen, A., ... Rutgeerts, P. (2011). Mucosal gene expression of cell adhesion molecules, chemokines, and chemokine receptors in patients with inflammatory bowel disease before and after infliximab treatment. Am J Gastroenterol, 106, 748-761. https://doi.org/10.1038/ajg.2011.27 
Bermúdez, R., Losada, A. P., Vázquez, S., Redondo, M. J., Álvarez-Pellitero, P., \& Quiroga, M. I. (2010). Light and electron microscopic studies on turbot Psetta maxima infected with Enteromyxum scophthalmi: Histopathology of turbot enteromyxosis. Dis Aquat Organ, 89, 209-221. https://doi.org/10.3354/dao02202

Bermúdez, R., Vigliano, F., Marcaccini, A., Sitjà-Bobadilla, A., Quiroga, M. I., \& Nieto, J. M. (2006). Response of Ig-positive cells to Enteromyxum scophthalmi (Myxozoa) experimental infection in turbot, Scophthalmus maximus (L.): A histopathological and immunohistochemical study. Fish Shellfish Immunol, 21, 501-512. https://doi.org/10.1016/j.fsi.2006.02.006

Cavey, M., \& Lecuit, T. (2009). Molecular Bases of Cell-Cell Junctions Stability and Dynamics. Cold Spring Harbor Perspectives in Biology, 1(5). https://doi.org/10.1101/cshperspect.a002998

Chang, E. S., Neuhof, M., Rubinstein, N. D., Diamant, A., Philippe, H., Huchon, D., \& Cartwright, P. (2015). Genomic insights into the evolutionary origin of Myxozoa within Cnidaria. Proc Natl Acad Sci U S A, 112, 14912-14917. https://doi.org/10.1073/pnas.1511468112

Chelakkot, C., Ghim, J., \& Ryu, S. H. (2018). Mechanisms regulating intestinal barrier integrity and its pathological implications. Experimental \& Molecular Medicine, 50(8), 1-9. https://doi.org/10.1038/s12276-018-0126-x

Cuadrado, M., Marques, A., Diamant, A., Sitjà-Bobadilla, A., Palenzuela, O., Alvarez-Pellitero, P., ... Crespo, S. (2008). Ultrastructure of Enteromyxum leei (Diamant, Lom, \& Dyková, 1994) (Myxozoa), an Enteric Parasite Infecting Gilthead Sea Bream (Sparus aurata) and Sharpsnout Sea Bream (Diplodus puntazzo). Journal of Eukaryotic Microbiology, 55(3), 178-184. https://doi.org/10.1111/j.1550-7408.2008.00325.x 
Di Genova, B. M., \& Tonelli, R. R. (2016). Infection Strategies of Intestinal Parasite Pathogens and Host Cell Responses. Frontiers in Microbiology, 7. https://doi.org/10.3389/fmicb.2016.00256

Estensoro, I., Ballester-Lozano, G., Benedito-Palos, L., Grammes, F., Martos-Sitcha, J. A., Mydland, L.-T., ... Pérez-Sánchez, J. (2016). Dietary Butyrate Helps to Restore the Intestinal Status of a Marine Teleost (Sparus aurata) Fed Extreme Diets Low in Fish Meal and Fish Oil. PLOS ONE, 11(11), e0166564. https://doi.org/10.1371/journal.pone.0166564

Estensoro, I., Benedito-Palos, L., Palenzuela, O., Kaushik, S., Sitjà-Bobadilla, A., \& PérezSánchez, J. (2011). The nutritional background of the host alters the disease course in a fish-myxosporean system. Vet Parasitol, 175, 141-150. http://dx.doi.org/10.1016/j.vetpar.2010.09.015

Estensoro, I., Calduch-Giner, J. A., Kaushik, S., Pérez-Sánchez, J., \& Sitjà-Bobadilla, A. (2012). Modulation of the IgM gene expression and IgM immunoreactive cell distribution by the nutritional background in gilthead sea bream (Sparus aurata) challenged with Enteromyxum leei (Myxozoa). Fish Shellfish Immunol, 33, 401-410. https://doi.org/10.1016/j.fsi.2012.05.029

Estensoro, I., Jung-Schroers, V., Álvarez-Pellitero, P., Steinhagen, D., \& Sitjà-Bobadilla, A. (2013). Effects of Enteromyxum leei (Myxozoa) infection on gilthead sea bream (Sparus aurata) (Teleostei) intestinal mucus: Glycoprotein profile and bacterial adhesion. Parasitology Research, 112(2), 567-576. https://doi.org/10.1007/s00436-012-3168-3

Estensoro, I., Redondo, M. J., Alvarez-Pellitero, P., \& Sitjà-Bobadilla, A. (2010). Novel horizontal transmission route for Enteromyxum leei (Myxozoa) by anal intubation of gilthead sea bream Sparus aurata. Diseases of Aquatic Organisms, 92(1), 51-58. https://doi.org/10.3354/dao02267 
Estensoro, I., Redondo, M. J., Salesa, B., Kaushik, S., Pérez-Sánchez, J., \& Sitjà-Bobadilla, A. (2012). Effect of nutrition and Enteromyxum leei infection on gilthead sea bream Sparus aurata intestinal carbohydrate distribution. Diseases of Aquatic Organisms, 100(1), 29-42. https://doi.org/10.3354/dao02486

Fleurance, R., Sauvegrain, C., Marques, A., Le Breton, A., Guereaud, C., Cherel, Y., \& Wyers, M. (2008). Histopathological changes caused by Enteromyxum leei infection in farmed sea bream Sparus aurata. Dis Aquat Organ, 79, 219-228. https://doi.org/10.3354/dao01832

Fouquet, S., Lugo-Martinez, V. H., Faussat, A. M., Renaud, F., Cardot, P., Chambaz, J., ... Thenet, S. (2004). Early loss of E-cadherin from cell-cell contacts is involved in the onset of Anoikis in enterocytes. J Biol Chem, 279, 43061-43069. https://doi.org/10.1074/jbc.M405095200

Gisbert, E., Andree, K. B., Quintela, J. C., Calduch-Giner, J. A., Ipharraguerre, I. R., \& PérezSánchez, J. (2017). Olive oil bioactive compounds increase body weight, and improve gut health and integrity in gilthead sea bream (Sparus aurata). British Journal of Nutrition, 117(3), 351-363. https://doi.org/10.1017/S0007114517000228

Gruhl, A., \& Okamura, B. (2015). Tissue Characteristics and Development in Myxozoa. In B. Okamura, A. Gruhl, \& J. L. Bartholomew (Eds.), Myxozoan Evolution, Ecology and Development (pp. 155-174). https://doi.org/10.1007/978-3-319-14753-6_9

Hu, H., Kortner, T. M., Gajardo, K., Chikwati, E., Tinsley, J., \& Krogdahl, A. (2016). Intestinal Fluid Permeability in Atlantic Salmon (Salmo salar L.) Is Affected by Dietary Protein Source. PLoS One, 11, e0167515. https://doi.org/10.1371/journal.pone.0167515 Hulpiau, P., \& van Roy, F. (2011). New insights into the evolution of metazoan cadherins. Mol Biol Evol, 28, 647-657. https://doi.org/10.1093/molbev/msq233 Inagaki-Ohara, K., Dewi, F. N., Hisaeda, H., Smith, A. L., Jimi, F., Miyahira, M., ... Nawa, Y. (2006). Intestinal Intraepithelial Lymphocytes Sustain the Epithelial Barrier Function 
against Eimeria vermiformis Infection. Infection and Immunity, 74(9), 5292-5301.

Kamekura, R., Nava, P., Feng, M., Quiros, M., Nishio, H., Weber, D. A., ... Nusrat, A. (2015). Inflammation-induced desmoglein-2 ectodomain shedding compromises the mucosal barrier. Mol Biol Cell, 26, 3165-3177. https://doi.org/10.1091/mbc.E15-03-0147

Larkin, M. A., Blackshields, G., Brown, N. P., Chenna, R., McGettigan, P. A., McWilliam, H., ... Higgins, D. G. (2007). Clustal W and Clustal X version 2.0. Bioinformatics, 23(21), 2947-

Liu, Y., Beyer, A., Aebersold, R. (2016). On the Dependency of Cellular Protein Levels on mRNA Abundance. Cell, 165(3), 535-550. https://doi.org/10.1016/j.cell.2016.03.014

Livak, K. J., \& Schmittgen, T. D. (2001). Analysis of relative gene expression data using real-time quantitative PCR and the 2(-Delta C(T)) Method. Methods, 25, 402-408. https://doi.org/10.1006/meth.2001.1262

Losada, A. P., Bermúdez, R., Faílde, L. D., de Ocenda, M. V. R., \& Quiroga, M. I. (2014). Study of the distribution of active caspase-3-positive cells in turbot, Scophthalmus maximus (L.), enteromyxosis. J Fish Dis, 37, 21-32. https://doi.org/10.1111/jfd.12029

Losada, A. P., Bermúdez, R., Faílde, L. D., \& Quiroga, M. I. (2012). Quantitative and qualitative evaluation of iNOS expression in turbot (Psetta maxima) infected with Enteromyxum scophthalmi. Fish Shellfish Immunol, 32, 243-248. https://doi.org/10.1016/j.fsi.2011.11.007

Palenzuela, O., Redondo, M. J., López, E., \& Álvarez-Pellitero, P. (2007). Cultured sole, Solea senegalensis is susceptible to Enteromyxum scophthalmi, the myxozoan parasite causing turbot emaciative enteritis. Parassitologia, 49, 73.

Pérez-Cordón, G., Estensoro, I., Benedito-Palos, L., Calduch-Giner, J. A., Sitjà-Bobadilla, A., \& Pérez-Sánchez, J. (2014). Interleukin gene expression is strongly modulated at the local 
level in a fish-parasite model. Fish Shellfish Immunol, 37, 201-208.

$$
\text { http://dx.doi.org/10.1016/j.fsi.2014.01.022 }
$$

Pérez-Sánchez, J., Benedito-Palos, L., Estensoro, I., Petropoulos, Y., Calduch-Giner, J. A., Browdy, C. L., \& Sitjà-Bobadilla, A. (2015). Effects of dietary NEXT ENHANCE ${ }^{\circledR} 150$ on growth performance and expression of immune and intestinal integrity related genes in gilthead sea bream (Sparus aurata L.). Fish \& Shellfish Immunology, 44(1), 117-128. https://doi.org/10.1016/j.fsi.2015.01.039

Pérez-Sánchez, J., Estensoro, I., Redondo, M. J., Calduch-Giner, J. A., Kaushik, S., \& SitjàBobadilla, A. (2013). Mucins as Diagnostic and Prognostic Biomarkers in a Fish-Parasite Model: Transcriptional and Functional Analysis. PLOS ONE, 8(6), e65457. https://doi.org/10.1371/journal.pone.0065457

Picard-Sánchez, A., Cañizares, J., Ziarsolo, P., Blanca, J., Montero-Pau, J., Sitjà-Bobadilla, A., \& Palenzeula, O. (2017). Filtering and characterization of Enteromyxum spp (Myxozoa) transcriptomes from RNAseq data. 18th International Conference on Diseases of Fish and Shellfish. Presented at the 18th International Conference on Diseases of Fish and Shellfish, Belfast, UK.

Picard-Sánchez, Amparo, Estensoro, I., del Pozo, R., Piazzon, M. C., Palenzuela, O., \& SitjàBobadilla, A. (2019). Acquired protective immune response in a fish-myxozoan model encompasses specific antibodies and inflammation resolution. Fish \& Shellfish Immunology, 90, 349-362. https://doi.org/10.1016/j.fsi.2019.04.300

Rao, R. K., Basuroy, S., Rao, V. U., Karnaky, K. J., \& Gupta, A. (2002). Tyrosine phosphorylation and dissociation of occludin-ZO-1 and E-cadherin-beta-catenin complexes from the cytoskeleton by oxidative stress. The Biochemical Journal, 368(Pt 2), 471-481. https://doi.org/10.1042/BJ20011804

Redondo, M. J., \& Álvarez-Pellitero, P. (2009). Lectinhistochemical detection of terminal carbohydrate residues in the enteric myxozoan Enteromyxum leei parasitizing gilthead 

electron microscopy. Folia Parasitol (Praha), 56, 259-267.

Redondo, M. J., \& Álvarez-Pellitero, P. (2010a). Carbohydrate patterns in the digestive tract of Sparus aurata L. and Psetta maxima (L.) (Teleostei) parasitized by Enteromyxum leei and E. scophthalmi (Myxozoa). Parasitology International, 59, 445-453.

Redondo, M. J., \& Álvarez-Pellitero, P. (2010b). The effect of lectins on the attachment and invasion of Enteromyxum scophthalmi (Myxozoa) in turbot (Psetta maxima L.) intestinal epithelium in vitro. Exp Parasitol, 126, 577-581. https://doi.org/10.1016/j.exppara.2010.06.008

Redondo, M. J., Palenzuela, O., \& Álvarez-Pellitero, P. (2004). Studies on transmission and life cycle of Enteromyxum scophthalmi (Myxozoa), an enteric parasite of turbot Scophthalmus maximus. Folia Parasitol (Praha), 51, 188-198. https://doi.org/10.14411/fp.2004.022

Redondo, M. J., Palenzuela, O., Riaza, A., Macías, A., \& Álvarez-Pellitero, P. (2002). Experimental transmission of Enteromyxum scophthalmi (Myxozoa), an enteric parasite of turbot Scophthalmus maximus. J Parasitol, 88, 482-488. https://doi.org/10.1645/0022-3395(2002)088[0482:ETOESM]2.0.CO;2

Redondo, M. J., Quiroga, M. I., Palenzuela, O., Nieto, J. M., \& Álvarez-Pellitero, P. (2003). Ultrastructural studies on the development of Enteromyxum scophthalmi (Myxozoa), an enteric parasite of turbot (Scophthalmus maximus L.). Parasitol Res, 90, 192-202. https://doi.org/10.1007/s00436-002-0810-5

Rigos, G., \& Katharios, P. (2010). Pathological obstacles of newly-introduced fish species in Mediterranean mariculture: A review. Reviews in Fish Biology and Fisheries, 20, 47-70. https://doi.org/10.1007/s11160-009-9120-7 
Robledo, D., Hernández-Urcera, J., Cal, R. M., Pardo, B. G., Sánchez, L., Martínez, P., \& Vinas, A. (2014). Analysis of qPCR reference gene stability determination methods and a practical approach for efficiency calculation on a turbot (Scophthalmus maximus) gonad dataset. BMC Genomics, 15, 648. https://doi.org/10.1186/1471-2164-15-648

Robledo, D., Ronza, P., Harrison, P. W., Losada, A. P., Bermúdez, R., Pardo, B. G., ... Martínez, P. (2014). RNA-seq analysis reveals significant transcriptome changes in turbot (Scophthalmus maximus) suffering severe enteromyxosis. BMC Genomics, 15, 1149. https://doi.org/10.1186/1471-2164-15-1149

Ronza, P., Robledo, D., Bermúdez, R., Losada, A. P., Pardo, B. G., Martínez, P., \& Quiroga, M. I. (2019). Integrating Genomic and Morphological Approaches in Fish Pathology Research: The Case of Turbot (Scophthalmus maximus) Enteromyxosis. Frontiers in Genetics, 10, 26. https://doi.org/10.3389/fgene.2019.00026

Ronza, P., Villamarín, A., Méndez, L., Pardo, B. G., Bermúdez, R., \& Quiroga, M. I. (2019). Immunohistochemical expression of E-cadherin in different tissues of the teleost fish Scophthalmus maximus. Aquaculture, 501, 465-472. https://doi.org/10.1016/j.aquaculture.2018.12.009

Sanders, D. S. (2005). Mucosal integrity and barrier function in the pathogenesis of early lesions in Crohn's disease. J Clin Pathol, 58, 568-572. https://doi.org/10.1136/jcp.2004.021840

Schneider, M. R., Dahlhoff, M., Horst, D., Hirschi, B., Trülzsch, K., Müller-Höcker, J., ... Kolligs, F. T. (2010). A Key Role for E-cadherin in Intestinal Homeostasis and Paneth Cell Maturation. PLOS ONE, 5(12). https://doi.org/10.1371/journal.pone.0014325

Shao, X., Kang, H., Loveless, T., Lee, G. R., Seok, C., Weis, W. I., ... Hardin, J. (2017). Cell-cell adhesion in metazoans relies on evolutionarily conserved features of the $\alpha$-catenin· $\beta$ catenin-binding interface. The Journal of Biological Chemistry, 292(40), 16477-16490. https://doi.org/10.1074/jbc.M117.795567 
Shpirer, E., Chang, E. S., Diamant, A., Rubinstein, N., Cartwright, P., \& Huchon, D. (2014). Diversity and evolution of myxozoan minicollagens and nematogalectins. BMC Evol Biol, 14, 205. https://doi.org/10.1186/s12862-014-0205-0

Simó-Mirabet, P., Piazzon, M. C., Calduch-Giner, J. A., Ortiz, Á., Puyalto, M., Sitjà-Bobadilla, A., \& Pérez-Sánchez, J. (2017). Sodium salt medium-chain fatty acids and Bacillus-based probiotic strategies to improve growth and intestinal health of gilthead sea bream (Sparus aurata). PeerJ, 5, e4001-e4001. https://doi.org/10.7717/peerj.4001

Sitjà-Bobadilla, A., \& Palenzuela, O. (2012). Enteromyxum Species. In P. T. K. Woo \& K. Buchmann (Eds.), Fish Parasites: Pathobiology and Protection (pp. 163-176). UK: CABI publishing.

Vogel, C., \& Marcotte, E. M. (2012). Insights into the regulation of protein abundance from proteomic and transcriptomic analyses. Nature Reviews. Genetics, 13(4), 227-232. https://doi.org/10.1038/nrg3185

\section{Supporting information}

(Additional supporting information may be found online in the Supporting Information section)

Supporting File 1. Alignment of E-cadherin nucleotide sequences of turbot (MG137250.1) and gilthead sea bream (KF861995.1). The locations of the primer recognition sites are indicated by arrows. 


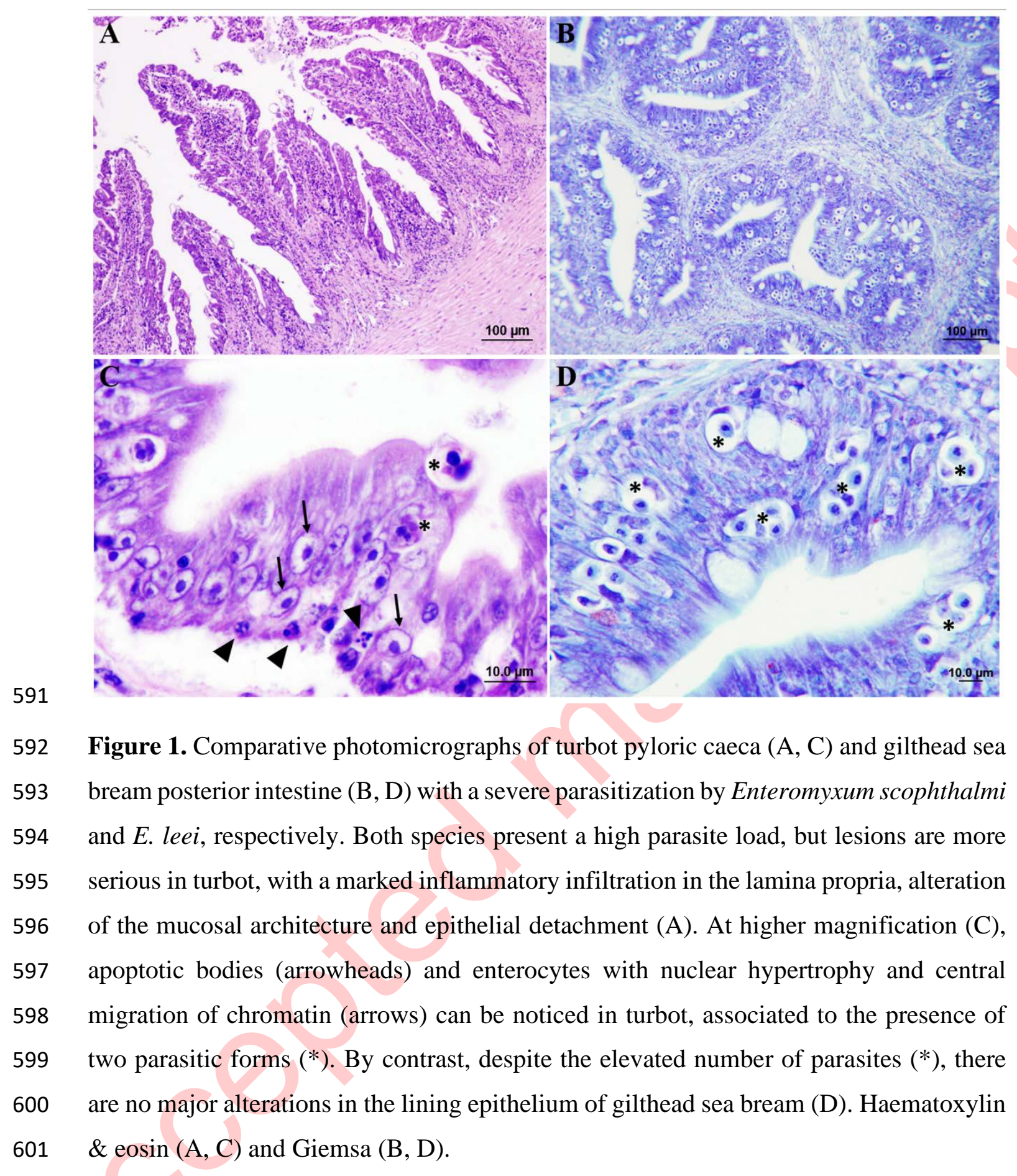



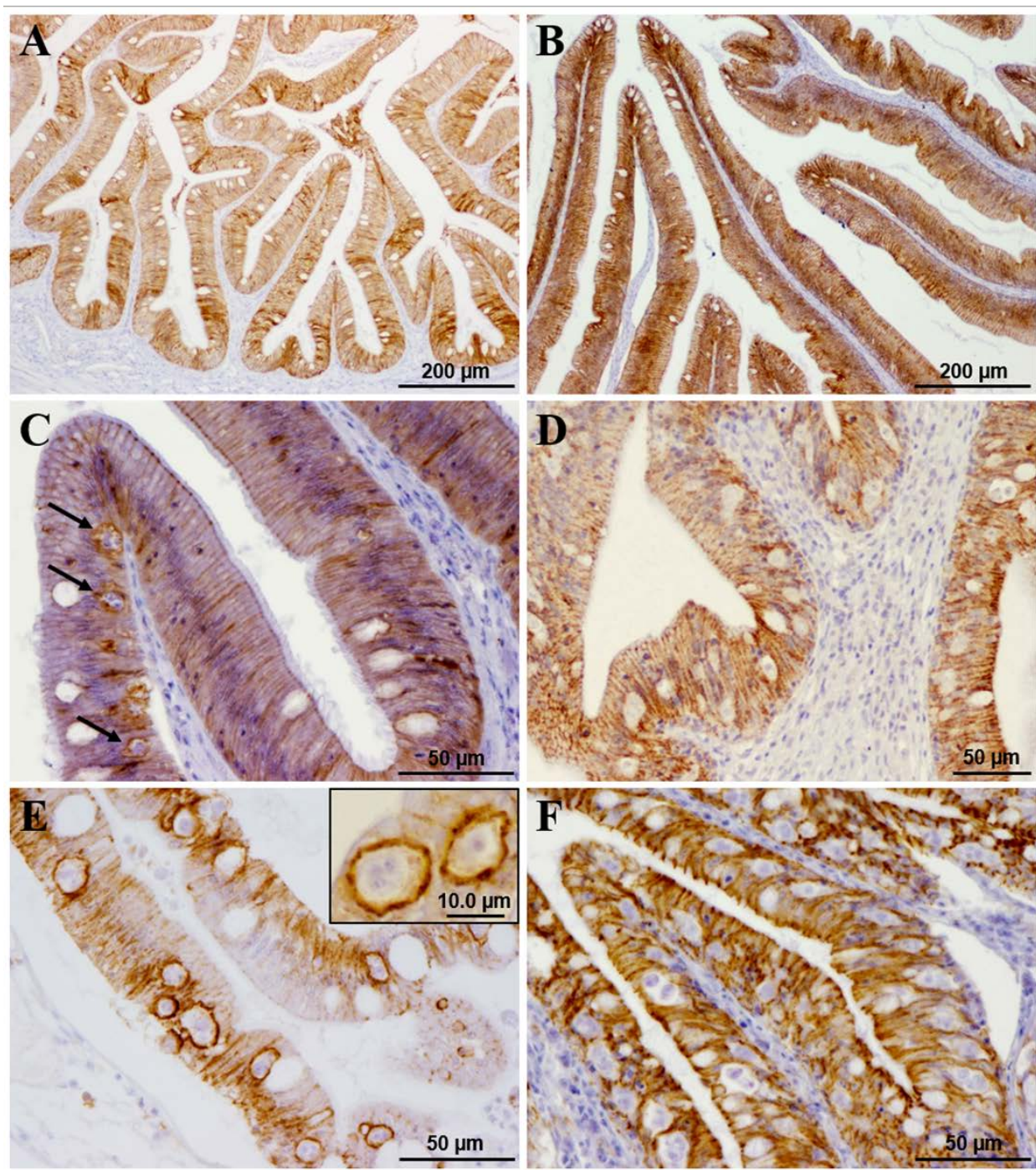

602

Figure 2. Immunohistochemical detection of E-cadherin in turbot (A, C, E) and gilthead

604

605

606

607

608

609

610

611

612

613

614

615

616

sea bream (B, D, F) intestine. A, B = Control fish; C, D = Enteromyxum-infected fish with moderate infection; E, F = Enteromyxum-infected fish with severe infection. A, B) E-cadherin immunostaining in control fish showed a regular distribution with immunolocalization at cell-cell contacts in the intestinal mucosa. Bars $=200 \mu \mathrm{m}$. C) In moderately infected turbot the general distribution pattern of E-cadherin was conserved, but a more intense immunoreaction was noticed surrounding the parasitic forms (arrows). Bar $=50 \mu \mathrm{m}$. D) No outstanding changes in E-cadherin distribution were noticed in gilthead sea bream with moderate infection. Bar $=50 \mu \mathrm{m}$. E) The immunostaining was markedly altered in severely parasitized turbot, with areas of scant immunoreaction and a strong label intensity at the contact areas between host and parasites (see inset). Bar = $50 \mu \mathrm{m}$; Inset bar $=20 \mu \mathrm{m}$. F) Even in case of advanced enteromyxosis with a massive parasite load in the epithelium, E-cadherin immunostaining was not significantly affected in gilthead sea bream sections. Bar $=50 \mu \mathrm{m}$. 

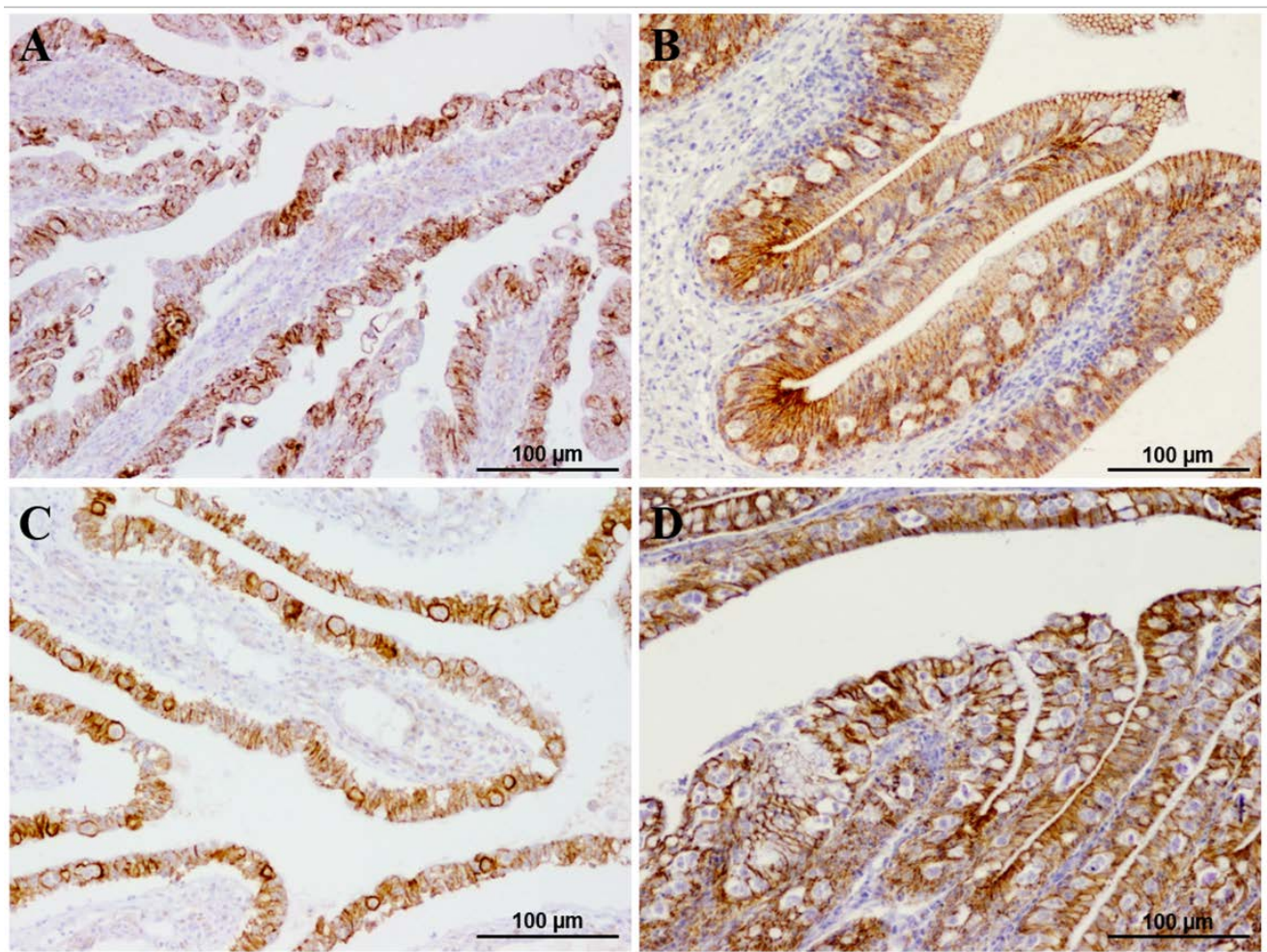

618 Figure 3. Comparative photomicrographs of E-cadherin immunostaining in the anterior gilthead sea bream (B, D). Bars $=100 \mu \mathrm{m}$.

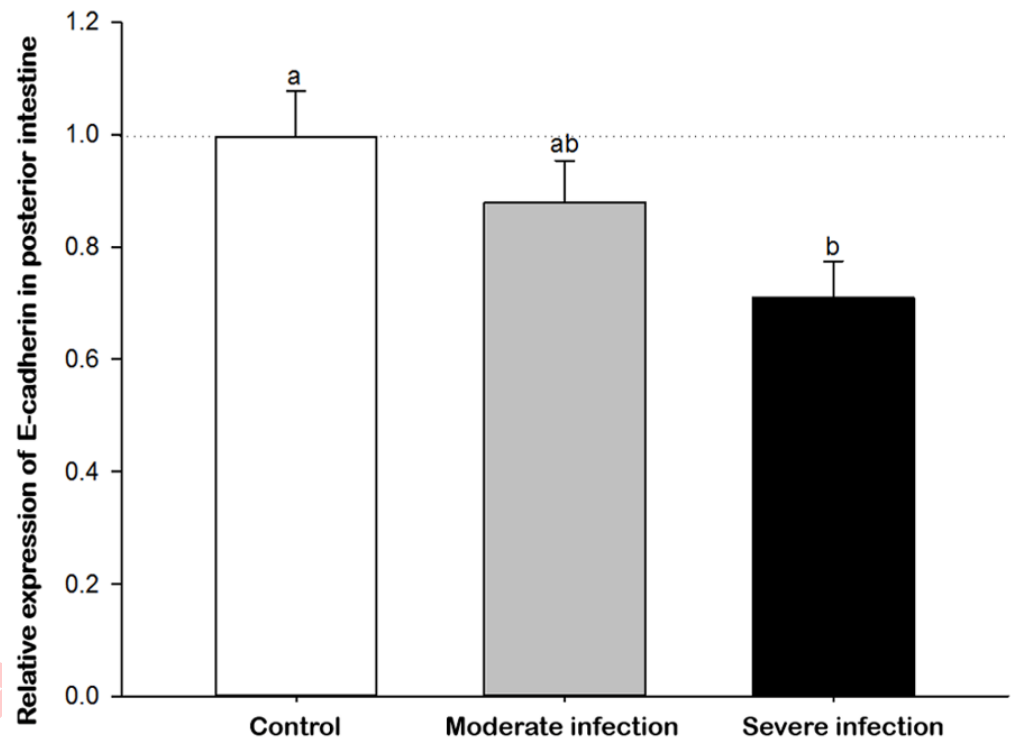

622 Figure 4. Mean and standard error of the mean of E-cadherin transcript levels in gilthead

623 sea bream posterior intestine. Control, moderately and severely Enteromyxum-infected

624 fish were analysed. The transcript levels in control fish were used as references values

625 (values $>1$ or $<1$ indicate increase or decrease with respect to the reference). Different 626 letters indicate statistically significant differences $(\mathrm{P}<0.05)$. 

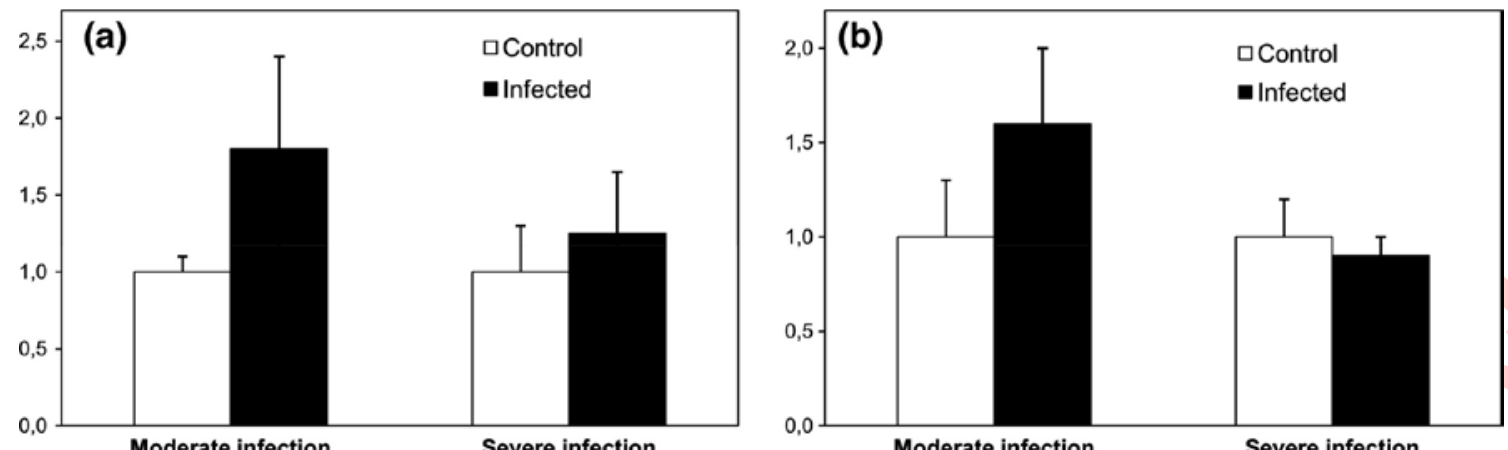

630 Figure 5. Mean and standard error of the mean of E-cadherin transcript levels in turbot pyloric caeca (A) and posterior intestine (B). Moderately and severely Enteromyxum632 infected fish at 24 and 42 days post-infection, respectively, were analysed. The transcript 633 levels in the respective control fish groups were used as references values (values $>1$ or $634<1$ indicate increase or decrease with respect to the reference). 